\title{
A study on the design improvement of protective footwear for firefighters
}

\author{
Minyoung Kang ${ }^{1}$ and Sunhee Lee ${ }^{2^{*}}$
}

\author{
*Correspondence: \\ shlee014@dau.ac.kr \\ ${ }^{2}$ Department of Fashion \\ Design, Dong-A University, \\ Busan 49315, South Korea \\ Full list of author information \\ is available at the end of the \\ article
}

\begin{abstract}
In this study, protective footwear for firefighters in Korea was evaluated. Based on the results of wearing evaluation, three types of new designs of firefighting protective footwear were developed: prototypes I, I and II. The prototypes with improved designs were evaluated by wear trails and design preference. Surveys on wearing and design preference of firefighting protective footwear, led to suggestions for designs elements of protective footwear. Firstly, the combination of laces and buckle was suggested for the closure. Secondly, the footwear material suggested was artificial leather with excellent waterproof and ventilation standards. In addition, retro-reflective and fluorescent materials and various colors were suggested for visibility. Thirdly, appearance designs were suggested in three categories: figure, line, and arrangement. Based on the design suggestions, prototypes with improved designs were made. An evaluation was conducted wearing the prototypes with improved designs. All prototypes were found to satisfy more than half of the design and wearing evaluation categories.
\end{abstract}

Keywords: Firefighter, Protective footwear, Design improvement, Prototype, Evaluation upon wearing

\section{Introduction}

According to KFIS 008 (Korea Fire Institute Standards (KFIS) 2001), protective footwear for firefighters must protect the human body from various dangerous elements including an extreme external environment, heat, fire, chemical substances, sharp objects, and shock. They must also maximize movement, and provide safety and comfort for firefighters who work in extreme conditions. The structure of protective footwear for firefighters consists of the main body, inner sole, protective sole, lining, shin guard, outer sole, and slip prevention grooves. There are two types footwear: rubber footwear and leather footwear. Rubber footwear uses vulcanized rubber on the outside, and aramid fiber for the lining, and has a pulling loop-type opening. Leather footwear has leather material on the outside, penetration prevention fabric on the inside, and a zipper-type opening. According to KFIS 008 (KFIS 2001), protective footwear for firefighters in Korea must be at least $30 \mathrm{~cm}$ high from the bottom of the outer sole. When the heel and soles are attached to the upper leather, no metal parts such as nails or screws can be used. The weight limitation for rubber footwear is $2.8 \mathrm{~kg}$, and the limitation for leather footwear is $3.0 \mathrm{~kg}$. The evaluation categories for protective footwear for firefighters include tension, electricity-resistance, 
water-resistance, heat-resistance, heat transmission, and internal heat conduction. The international and domestic standards for protective footwear for firefighters include NFPA 1971 (National Fire Protection Association (NFPA) 2013), CSN EN 15090 (Safety Protection Standards (CSN EN) 2012), and ISO 15538 (International Organization for Standardization (ISO) 2001).

Published studies on protective footwear for firefighters include a study on wear of personal firefighting protection gear (Bang 2010), a study on the physiological reactions when climbing stairs wearing firefighting rubber footwear and firefighting leather footwear (Huang et al. 2009), and a study on the effects of leather firefighting protective footwear on physical sense of balance (Huh and Bang 2013). Bang (2010) found that the preferences of firefighters for protective gear was in the order of fire suit (3.10), general work wear (3.04), helmet (2.97), leather protective footwear (2.68), gloves (2.6), and rubber protective footwear (2.59). The results of satisfaction analysis of firefighting protection gear showed that satisfaction was highest in order of general work wear (3.21), helmet (3.17), fire suit (3.15), leather protective footwear (2.97), gloves (2.77), and rubber protective footwear (2.75). Analysis of the overall satisfaction of firefighters' protection gear indicated that there was a need to improve protective footwear for firefighters. The satisfaction rate of protective footwear for firefighters was low because of the thick material used for protection, and the weight and discomfort from metal parts, and bad storage conditions. Huang et al. (2009) conducted physiological analysis while climbing stairs wearing rubber protective footwear and leather protective footwear. Physical fatigue was lower for rubber footwear compared to leather footwear, and flexibility was higher at the knees and the back of the foot. However, there is a lack of studies that analyze designs of protective footwear for firefighters, and develop protective footwear according to the designs and review of current conditions, which could aid smoother field action for firefighters. Therefore, there is a need for a study that will provide specific points of improvement for protective footwear for firefighters, and develop a product based on these points, for improved protection and safe field activities of firefighters. Previous related studies include an analysis of protective footwear products for firefighters (Kang et al. 2015), a review of the current conditions of protective footwear worn by firefighters (Lee and An 2016), and an analysis of protective footwear products and design proposals (Jung et al. 2016). Kang et al. (2015) selected the latest protective footwear for firefighters of different countries and comparatively analyzed them. The products included Sancheong (http://www.sancheong.com), the US brand Globe (http:// www.globeturnoutgear.com/boots), the German brand Haix (http://www.haix.com), and the Chinese brand Penco (http://www.shpengke.com). The results confirmed that rubber protective footwear had excellent water resistance and elasticity while leather protective footwear had excellent ventilation, and diverse pattern changes were found to be possible in terms of design. Lee and An (2016) found that the majority of protective footwear for firefighters were in the size range between 260 and $270 \mathrm{~cm}$. The most common foot type was the Greek type, where the second toe is the longest, and regular foot arches were more common than arched or flat types. Jung et al. (2016) proposed two types of combined openings for protective footwear: laces and zipper, and laces and buckle. The laces and buckle type that can adjust size was chosen and thirty designs were proposed with this opening. 
The aim of this study is to develop ergonomic, high-sensitive protective footwear for firefighters that considers wearer convenience, based on improvements to protective footwear designs currently worn by firefighters in the field. The specific study goals are as follows: The current conditions of protective footwear worn by firefighters will be examined, designs will be created based on this information for development of a test product, and three designs will be selected for the final proposal. The test products will be created, a survey will be conducted on wearability of the products, and the results will be reported.

\section{Methods}

Review of current conditions of protective footwear worn by firefighters research subjects Figure 1 shows Korean firefighters wearing Sancheong protective footwear. Current footwear is specialized as follows; the weight is $1.3 \mathrm{~kg}$, size is $265 \mathrm{~cm}$, and used material is rubber. An online survey was conducted on 438 firefighters in Korea from December 1 to December 15, 2015, to examine the conditions of wearing the products. The most frequent size of footwear for firefighters was in the order of 260, 270, and 265. The most common foot type was the Greek type, and the normal foot arch was more frequent than the arch or flat types.

\section{Survey contents}

A survey was conducted to examine the current conditions of wearing protective footwear for firefighters. The survey consisted of 12 questions: three questions were on satisfaction of the firefighting belt, three were on comfort, three were on design, and three were on functionality.

\section{Satisfaction rate}

Firefighters were asked to rate how often they wear their protective footwear on a 5-point scale. Points of discomfort were divided into eight categories-hard material, narrow width, hard sole, discomfort for ankle, bad functionality, unattractive design,
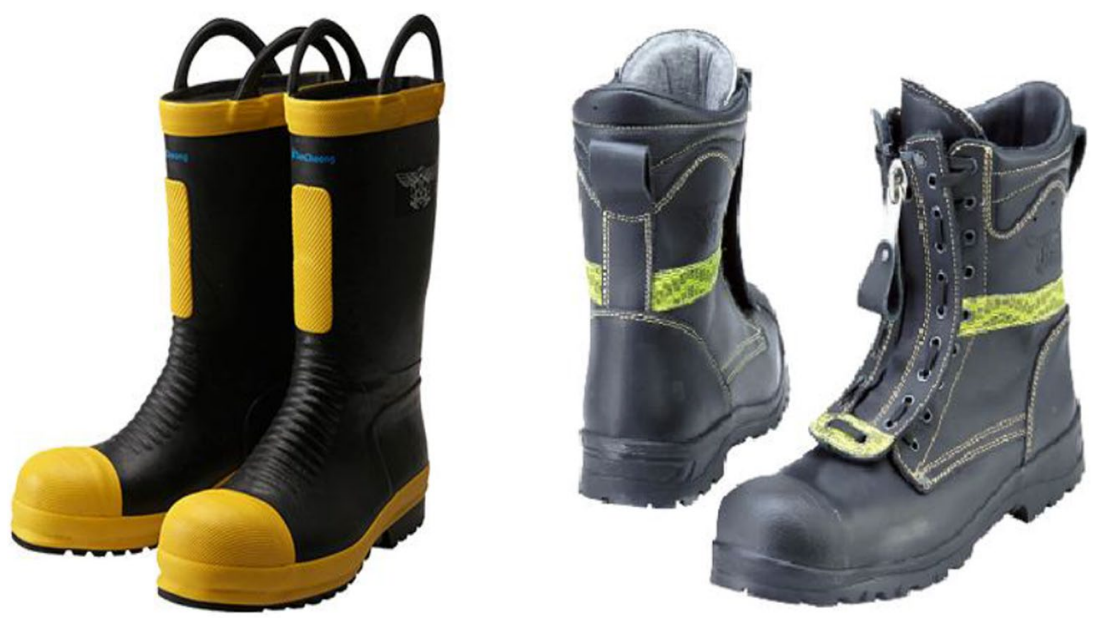

Fig. 1 Protective footwear for firefighters in Korea 
heavy weight, and other-and the respondents were asked to select at least one answer. Points considered when selecting protective footwear were divided into 11 categoriesbrand, design, price, size, color, material, weight, durability, functionality, after service, and other-and the respondents were asked to select at least one answer.

\section{Wearability}

The respondents were asked about whether or not they experienced injury after wearing protective footwear for long periods of time. Those who said they did were asked to choose at least one of the eight categories of blisters, redness and peeling, burn, swollen feet and tightness, foot aches, pain in sole of foot, pain from overlapped toes, and other. They were also asked to choose at least one of five reasons for injury: size, material, design, unique foot type, and other. Lastly, they were asked to write specific points of improvement.

\section{Design}

Satisfaction of design of existing protective footwear for firefighters was examined. Those who answered that they were dissatisfied were asked to choose one of four reasons: shape, color, material, other. They were also asked to choose at least one out of five categories for specific improvement areas: size allowance, ankle size, luminescence, opening, and other.

\section{Functionality}

Satisfaction of the functionality of protective footwear for firefighters was examined. Those who answered that they were dissatisfied were asked to choose one of size areas of function improvement: flame-resistance, water-resistance, ventilation, weight, zipper or cord opening, and other. They were also asked to choose at least one specific area of improvement: ease of wearing, shock-absorption, visibility, opening, and other.

\section{Statistical analysis}

SPSS for windows 22.0 (SPSS Inc. Chicago II, USA) was used to analyze frequency and percentages.

\section{Development and evaluation of improved protective footwear for firefighters Design selection and production}

Five experts, including two professors of clothing and textiles, and three graduate students of clothing and textiles, were asked to evaluate the designs. Three out of the 30 design improvements proposed by previous studies (Jung et al. 2016) on protective footwear for firefighters were selected. The three designs were submitted to the 4th Firefighting Industry Excellent Design Competition hosted by the Korea Fire Industry Technology Institute in June, 2016. The three design improvements submitted to the competition were produced as test products I, II, and III through a collaboration with the company Y. The appearance characteristics of each prototype are as follows. Prototype I used yellow as the point color, and placed a retroreflective fabric on the instep and the back of the foot. Prototype II was red and a retroreflective fabric was placed on the 
top. Prototype III included yellow and red colors, and a retroreflective fabric was applied as a stripe to the sides of the foot.

\section{Design and wearability evaluation survey}

A design and wearability evaluation survey for test products I, II, and III were conducted on October 24, 2016, at Moonkyung STX Resort. Fifty members of the city, do, and firefighting and emergency rescue industry were chosen as advisors and respondents of the survey. Surveys found to have unreliable answers were excluded, and a total of 38 surveys were analyzed. The surveys consisted of 17 questions. There were six questions on the design satisfaction of the test products, 10 questions on wearability and comfort satisfaction, and one subjective question. The design satisfaction questions asked about shape, color, materials, opening, sole, and overall design. The wearability questions asked about size, feel of material, weight, calves, ankles, foot width, foot sole, movability, fit, and overall wearability. SPSS for Windows 22.0 (SPSS Inc. Chicago II, USA) was used for analysis of frequency, percentage, average, and standard deviation.

\section{Results and discussion}

\section{Current conditions of wearing protective footwear for firefighters}

Table 1 shows the results of analysis of satisfaction rate of protective footwear for firefighters in Korea. The frequency of wearing protective footwear was found to be in order of 'normal' (170 respondents, 39.08\%), 'wear often' (105 respondents, 24.11\%), and 'wear very often' (91 respondents, 20.92\%). The biggest inconvenience of protective footwear was found to be 'Weight' (263 respondents, 24.40\%). Others included 'material' (190 respondents, 17.63\%), 'ankles' (171 respondents, 15.86\%), and 'functionality' (154 respondents, $14.29 \%)$. The factors considered when choosing protective footwear were 'functionality' (379 respondents, 31.55\%), 'durability' (252 respondents, 21.46\%), and 'weight' (234 respondents, $21.14 \%$ ). Table 2 shows the result of the functionality evaluation of current protective footwear for firefighters worn in Korea. When asked about functionality, 240 respondents (56.07\%) said they were 'dissatisfied. The areas of improvement were found to be 'weight' (71 respondents, 30.21\%), 'ventilation' (57 respondents, $24.26 \%$ ), and 'water-resistance' (43 respondents, 18.30\%). Specific areas of improvement were 'wearability' (226 respondents, 57.51\%), 'shock-absorption' (95 respondents, $24.71 \%$ ), and 'visibility' (20 respondents, 5.09\%). Table 3 shows the results of the wearability evaluation of protective footwear for firefighters, including whether or not they have experienced injuries wearing the products, inconveniences while wearing the products, and reasons for inconveniences. The analysis showed that 181 respondents (41.61\%) had experience of an injury while wearing the products. The injury types were 'foot sole pain' (95 respondents, 39.26\%), 'blisters' (30 respondents, 12.40\%), and 'foot edema' (26 respondents, 10.74\%). The reasons for the injuries were in order of 'material' (93 respondents, 52.84\%), 'size' (40 respondents, 22.73\%), and 'design' (23 respondents, $13.07 \%$ ). Table 4 shows the results of design evaluation of protective footwear for firefighters in Korea. The design satisfaction evaluation showed that 216 respondents (50.12\%) were 'dissatisfied. Points of improvement were 'material' (143 respondents, $67.45 \%)$, 'shape' (42 respondents, 19.81\%), and 'other' (16 respondents, $7.55 \%)$. Specific 
Table 1 Satisfaction of protective footwear for firefighters in Korea

\begin{tabular}{|c|c|}
\hline Classification & $\mathrm{N}(\%)$ \\
\hline \multicolumn{2}{|l|}{ Frequency } \\
\hline Worn very often & $91(20.92)$ \\
\hline Worn often & $105(24.11)$ \\
\hline Normal & $170(39.08)$ \\
\hline Hardly worn & $49(11.26)$ \\
\hline Never worn & $20(4.60)$ \\
\hline Total & $435(100.00)$ \\
\hline \multicolumn{2}{|c|}{ Inconvenience of shoes for firefighters } \\
\hline Weight & $263(24.40)$ \\
\hline Material & $190(17.63)$ \\
\hline Ankle & $171(15.86)$ \\
\hline Functionality & $154(14.29)$ \\
\hline Outsole & $112(10.39)$ \\
\hline Foot width & $81(7.51)$ \\
\hline Design & $59(5.47)$ \\
\hline Others & $48(4.45)$ \\
\hline Total & $1078(100.00)$ \\
\hline \multicolumn{2}{|c|}{ Part to consider when selecting shoes for firefighters } \\
\hline Functionality & $294(31.55)$ \\
\hline Durability & $200(21.46)$ \\
\hline Weight & $197(21.14)$ \\
\hline Size & $92(9.87)$ \\
\hline Material & 44 (4.72) \\
\hline Design & $36(3.86)$ \\
\hline Brand & $15(1.61)$ \\
\hline Color & $12(1.29)$ \\
\hline Price & $4(0.43)$ \\
\hline$A / S$ & $15(1.61)$ \\
\hline Others & $23(2.47)$ \\
\hline Total & $932(100.00)$ \\
\hline
\end{tabular}

points of improvement were 'ankle size' (185 respondents, 43.43\%), 'size allowance' (80 respondents, $18.78 \%$ ), and 'opening' (75 respondents, $17.61 \%$ ).

The points to be considered when improving protective footwear for firefighters, according to the results of the current conditions of wearing the products in Korea, are as follows. There is a need to improve the opening design for size improvements and closer contact at the ankles. There is also a need to improve material considering waterresistance, ventilation, and visibility. Therefore, the new designs proposed a laces and buckle opening instead of the existing pull cord and zipper type. This would make size adjustments possible and improve contact at the ankles. The material for the footwear was proposed as synthetic leather with high water-resistance and ventilation instead of the existing rubber.

\section{Design selection and development of protective footwear for firefighters}

Figure 2 shows the three improved designs of protective footwear for firefighters proposed in this study. The opening was changed from the pull cord and zipper to laces and 
Table 2 Functionality evaluation of protective footwear for firefighters in Korea

\begin{tabular}{lc}
\hline Classification & N (\%) \\
\hline Functionality satisfaction & $188(43.93)$ \\
Satisfaction & $240(56.07)$ \\
Unsatisfaction & $428(100.00)$ \\
Total & \\
Functionality improvements & $71(30.21)$ \\
Weight & $57(24.26)$ \\
Ventilation & $43(18.30)$ \\
Waterproof & $20(8.51)$ \\
Closure & $18(7.66)$ \\
Flame resistance & $26(11.06)$ \\
Others & \\
Specific improvements & $235(100.00)$ \\
Total & $226(57.51)$ \\
Wearing & $95(24.17)$ \\
Shock absorption & $20(5.09)$ \\
Visibility & $18(4.58)$ \\
Closure & $34(8.65)$ \\
Others & $393(100.00)$ \\
Total & \\
\hline
\end{tabular}

Table 3 Wearing evaluation of protective footwear for firefighters in Korea

\begin{tabular}{lc}
\hline Classification & N (\%) \\
\hline Injury experience when worn & $181(41.61)$ \\
Yes & $254(58.39)$ \\
No & $435(100.00)$ \\
Total & \\
Injury type in wearing & $95(39.26)$ \\
Foot sole pain & $30(12.40)$ \\
Blister & $26(10.74)$ \\
Foot edema & $22(9.09)$ \\
Foot paresthesia & $13(5.37)$ \\
Skin red dot & $10(4.13)$ \\
Toe overlap & $2(0.83)$ \\
Burns & $4(18.18)$ \\
Others & $242(100.00)$ \\
Total & \\
Elements of wearing inconvenience of shoes for firefighters & $93(52.84)$ \\
Material & $40(22.73)$ \\
Size & $23(13.07)$ \\
Design & $6(3.41)$ \\
Foot specificity & $14(7.95)$ \\
Others & $176(100.00)$ \\
Total &
\end{tabular}

buckles for size improvement and closer contact at the ankles. Instead of the existing black color, yellow, red, and retro-reflective grey were appropriately used. Sample I is the design that won a prize at the Firefighting Industry Excellent Design Competition. 
Table 4 Design evaluation of protective footwear for firefighters in Korea

\begin{tabular}{lc}
\hline Classification & N (\%) \\
\hline Design satisfaction & $215(49.88)$ \\
Satisfaction & $216(50.12)$ \\
Unsatisfaction & $431(100.00)$ \\
Total & \\
Design improvements & $143(67.45)$ \\
Material & $42(19.81)$ \\
Shape & $11(5.19)$ \\
Color & $16(7.55)$ \\
Others & $212(100.00)$ \\
Total & \\
Specific improvements & $185(43.43)$ \\
Ankle size & $80(18.78)$ \\
Ease & $75(17.61)$ \\
Closure & $45(10.56)$ \\
Lighting functionality & $41(9.62)$ \\
Others & $426(100.00)$ \\
Total & \\
\hline
\end{tabular}

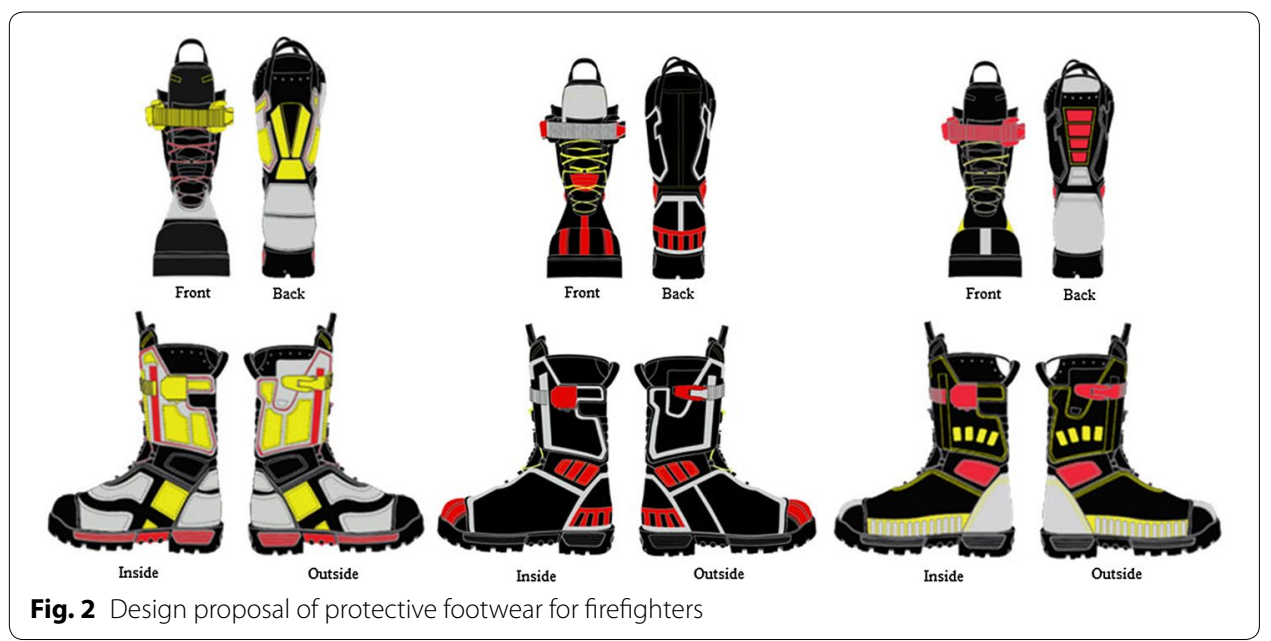

Figures 3, 4 and 5 show the pattern design plan of the three improved designs of protective footwear for firefighters, and the test products I, II, and III. The material used for the test products were synthetic leather and rubber. The opening that uses laces and buckles make it easy to wear and take off fast. Different size adjustments can be made to fit different body types, and there is closer contact at the ankles. All test prototypes, the size is $265 \mathrm{~cm}$ and the weight is about $1.3 \mathrm{~kg}$.

\section{Design and wearability evaluation survey on improved test products}

Table 5 shows the results of design satisfaction analysis of test products I, II, and III. The satisfaction of shape was in order of 'normal' (24 respondents, 64.90\%), 'dissatisfied' ( 9 respondents, $24.30 \%$ ), and 'very satisfied' (3 respondents, $8.10 \%$ ). The satisfaction of color was in order of 'satisfied' (24 respondents, 64.90\%), 'normal' (7 


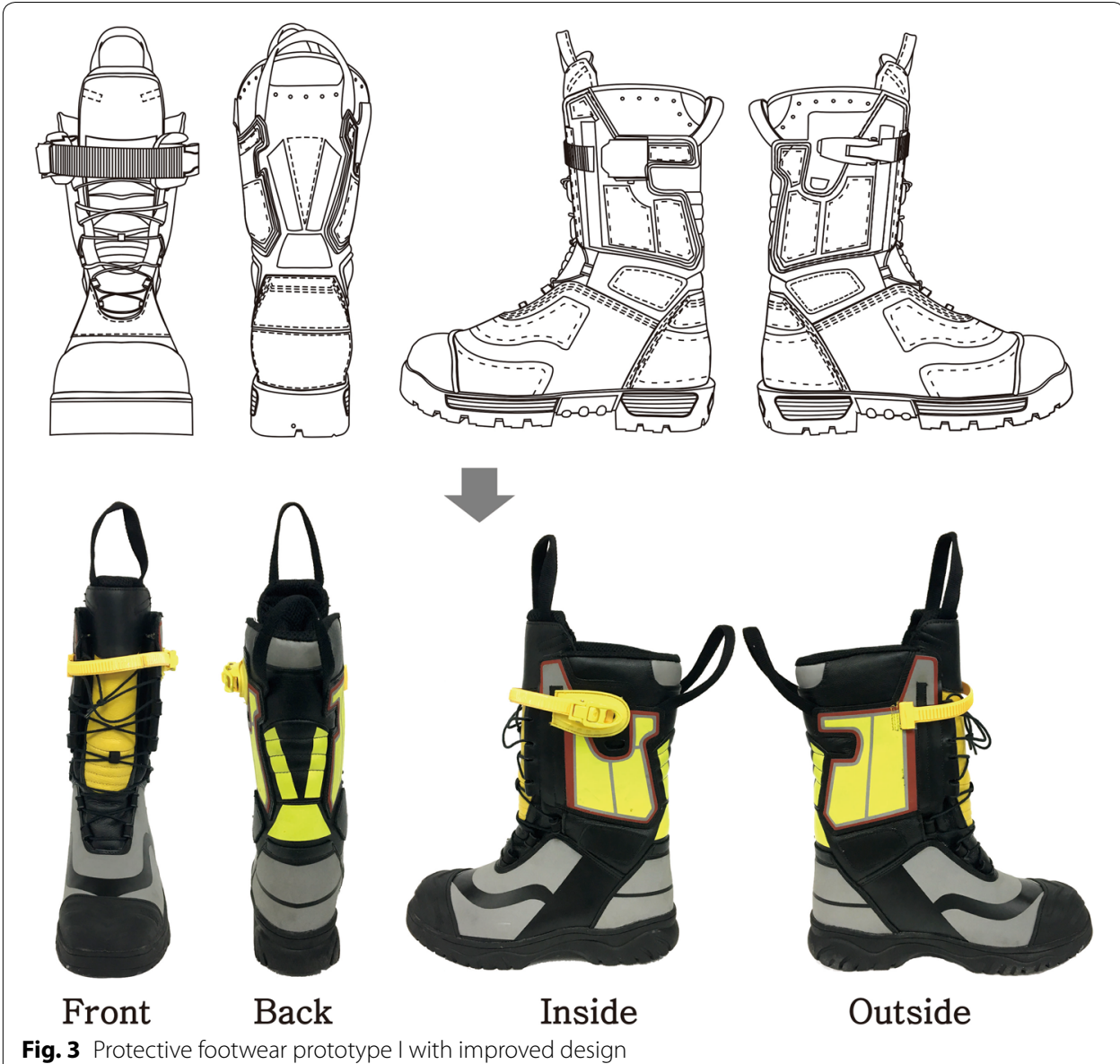

respondents, $18.90 \%$ ), and 'very satisfied' ( 4 respondents, $10.80 \%$ ). The satisfaction of material was in order of 'satisfied' (20 respondents, 58.80\%), 'normal' (9 respondents, $26.50 \%$ ), and 'dissatisfied' (3 respondents, $8.80 \%$ ). The satisfaction of closure was in order of 'satisfied' (16 respondents, 44.40\%), 'normal' (9 respondents, $25.00 \%$ ), and 'dissatisfied' (5 respondents, 13.90\%). The satisfaction of sole was in order of 'satisfied' (24 respondents, 70.30\%), 'normal' (6 respondents, 16.20\%), and 'very dissatisfied' (3 respondents, $8.10 \%)$. The overall design satisfaction rate was generally 'satisfied' (26 respondents, $70.30 \%)$.

Table 6 shows the results of wearability satisfaction analysis of test products I, II, and III. The satisfaction of size was in order of 'normal' (17 respondents, 47.20\%), 'satisfied' (13 respondents, 36.10\%), and 'very satisfied' (6 respondents, 16.70\%). The satisfaction of weight was in order of 'satisfied' (14 respondents, 37.80\%), 'normal' (13 respondents, 35.10\%), and 'dissatisfied' ( 8 respondents, $21.60 \%$ ). The evaluation showed that over $50 \%$ were satisfied with feel of material, calves, ankles, foot width, sole, movability, and fit. The overall wearability satisfaction was in order of 'satisfied' (16 respondents, 44.40\%), 'normal' (10 respondents, 27.80\%), and 'very satisfied' (5 respondents, $13.90 \%$ ), and over $58 \%$ were found to be satisfied. 

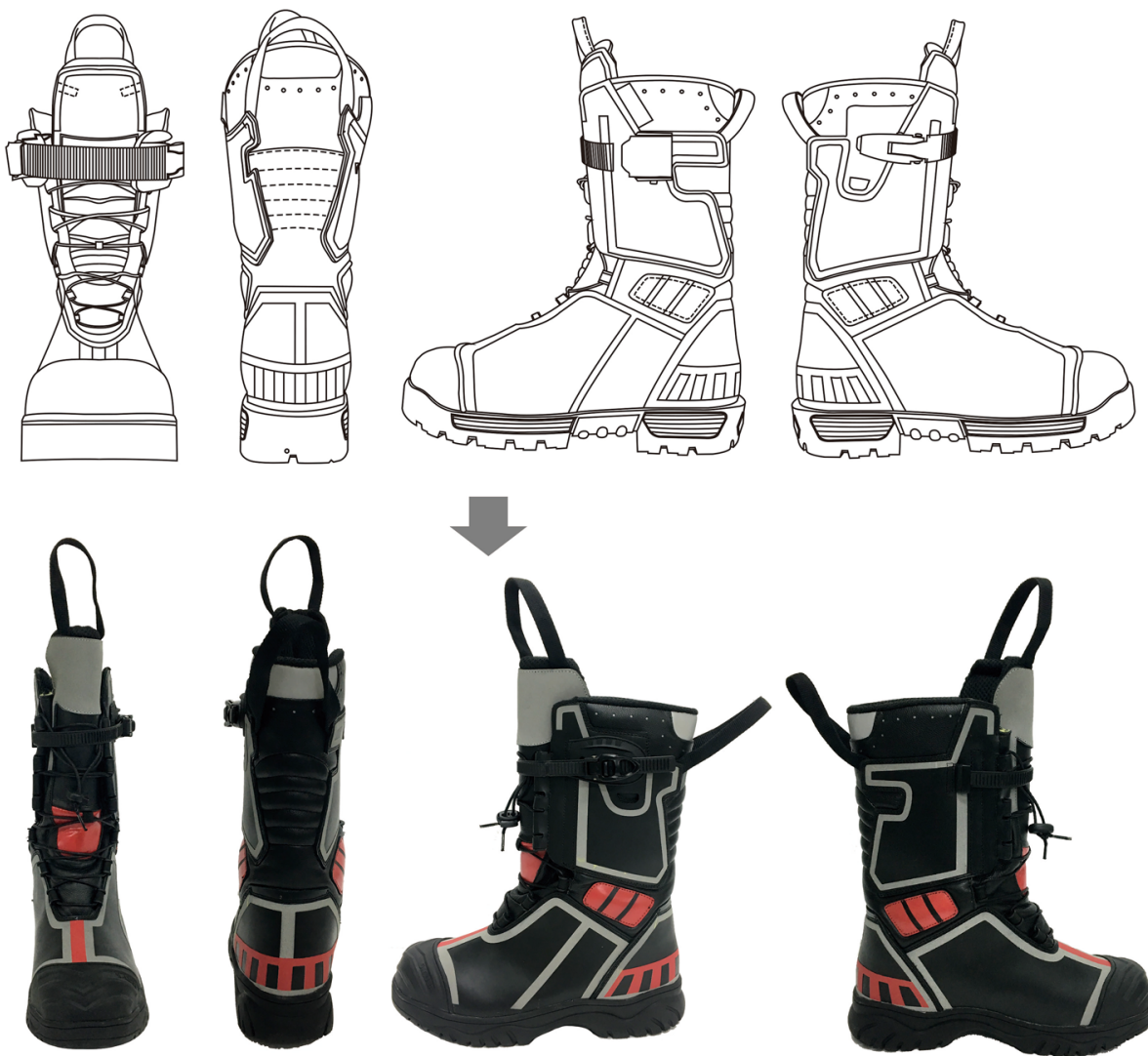

Front

Back

Inside

Fig. 4 Protective footwear prototype II with improved design

The answers to the subjective question on how to improve test product I included 'Opening should be improved because the size is small and cannot be adjusted', 'Longer laces so the calf area can be expanded for easier wearing', 'Heavier than existing waterproof footwear', 'Conduct wearability tests in high-rise buildings', 'Make it easier to pull the shoelaces', 'Would like a zipper opening,' 'The sole is too hard. I think it would be uncomfortable if worn for a long time' and 'Needs to be improved because it feels a bit bulky'. The answers to the subjective question on how to improve test product included 'A buckle can be uncomfortable when wearing a fire suit,' 'Need to improve tightness at ankles', 'Need to make lighter', 'Need to improve shock-absorption of soles,' 'Would like double layer buckles', 'Improve opening to velcro or another one-touch type system', and 'Add zipper opening. The answers to the subjective question on how to improve test product III included 'Need to improve soles. The foot is uncomfortable and it feels like I am carrying the shoe,' 'Feels like the buckle will get damaged easily', 'Need to change to a one-touch opening because it takes a long time to wear with a fire suit,' 'Need to improve material to make it lighter', 'Would like to different heights of footwear so the wearer can choose', 'Would like to be able to attach climbing irons to the soles', and 'Would like to add a non-slip function to the sole and make the front part stronger'. 


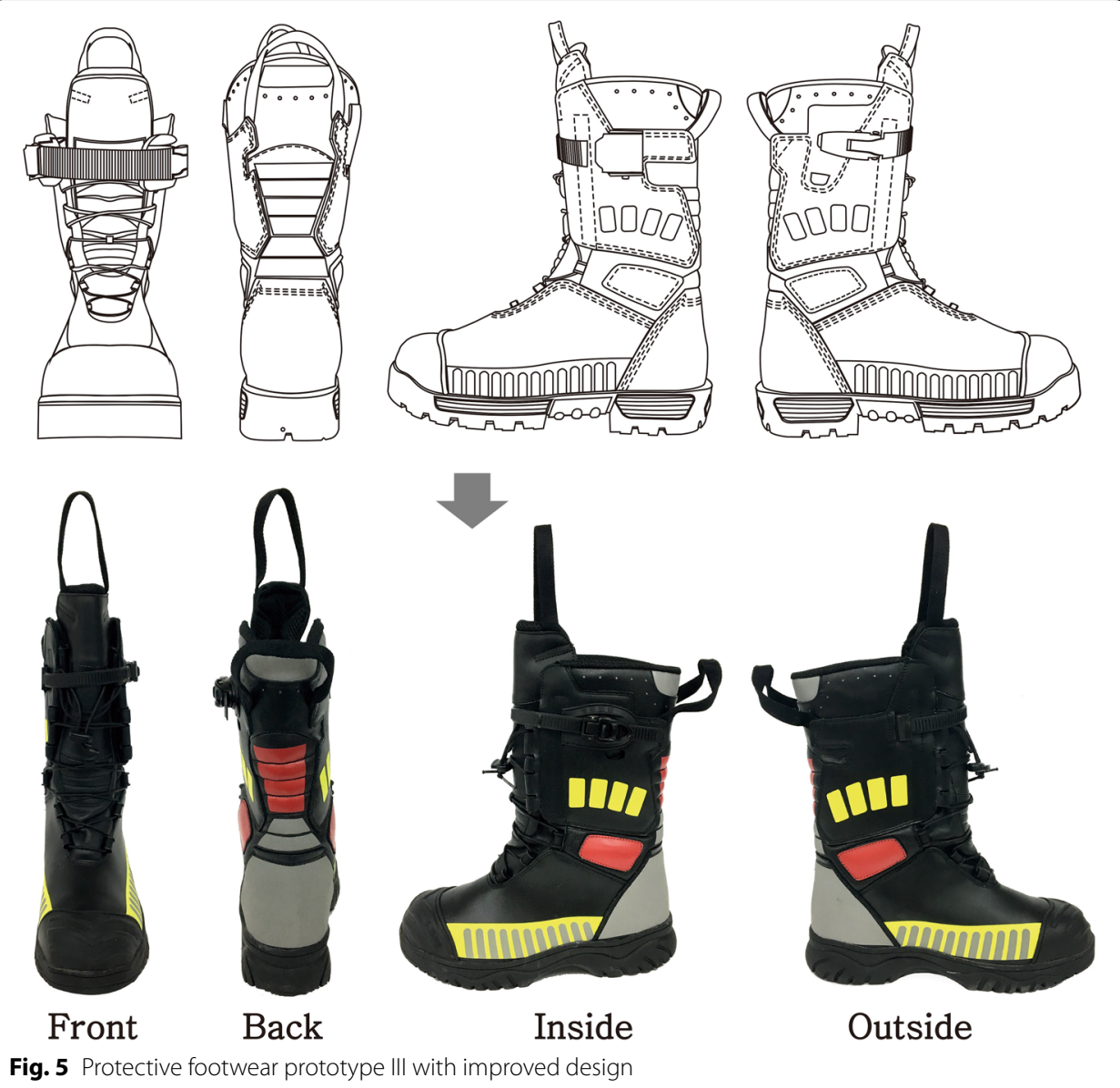

Table 5 Design satisfaction of improved design prototype (N/\%)

\begin{tabular}{lllllll}
\hline Classification & Very unsatisfied & Unsatisfied & Normal & Satisfied & Very satisfied & Mean (SD) \\
\hline $\begin{array}{llllll}\text { Design satisfaction } \\
\text { Shape }\end{array}$ & $1(2.70)$ & $9(24.30)$ & $24(64.90)$ & - & $3(8.10)$ & $3.76(0.72)$ \\
Color & $1(2.70)$ & $1(2.70)$ & $7(18.90)$ & $24(64.90)$ & $4(10.80)$ & $3.78(0.79)$ \\
Material & $1(2.90)$ & $3(8.80)$ & $9(26.50)$ & $20(58.80)$ & $1(2.90)$ & $3.50(0.83)$ \\
Closure & $4(11.10)$ & $5(13.90)$ & $9(25.00)$ & $16(44.40)$ & $2(5.60)$ & $3.19(1.12)$ \\
Shoes sole & $3(8.10)$ & $2(5.40)$ & $6(16.20)$ & $24(64.90)$ & $2(5.40)$ & $3.54(0.99)$ \\
Design & $1(2.70)$ & - & $9(24.30)$ & $26(70.30)$ & $1(2.70)$ & $3.70(0.66)$ \\
\hline
\end{tabular}

The results of the design and wearability evaluation survey on test products I, II, and III showed that more than half were satisfied with the overall design and wearability. 
Table 6 Wearing satisfaction of improved design prototype (N/\%)

\begin{tabular}{lllllll}
\hline Classification & Very unsatisfied & Unsatisfied & Normal & Satisfied & Very satisfied & Mean (SD) \\
\hline Wearing satisfaction & & & & & & \\
Size & - & - & $17(47.20)$ & $13(36.10)$ & $6(16.70)$ & $3.69(0.75)$ \\
Material feeling & - & $1(2.80)$ & $9(25.00)$ & $19(52.80)$ & $7(19.40)$ & $3.89(0.75)$ \\
Weight & - & $8(21.60)$ & $13(35.10)$ & $14(37.80)$ & $2(5.40)$ & $3.27(0.87)$ \\
Calf & - & $7(20.00)$ & $8(22.90)$ & $18(51.40)$ & $2(5.70)$ & $3.43(0.88)$ \\
Ankle & - & $4(11.10)$ & $11(30.60)$ & $19(52.80)$ & $2(5.60)$ & $3.53(0.77)$ \\
Foot width & - & $5(14.30)$ & $7(20.00)$ & $22(62.90)$ & $5(2.90)$ & $3.54(0.78)$ \\
Sole & $2(5.70)$ & $6(17.10)$ & $3(8.60)$ & $20(57.10)$ & $4(11.40)$ & $3.51(1.01)$ \\
Movement & $1(2.80)$ & $5(13.90)$ & $11(30.60)$ & $16(44.40)$ & $3(8.30)$ & $3.42(0.94)$ \\
Fitting & - & $4(11.40)$ & $12(34.30)$ & $16(45.70)$ & $3(8.60)$ & $3.51(0.82)$ \\
Wearing & - & $5(13.90)$ & $10(27.80)$ & $16(44.40)$ & $5(13.90)$ & $3.58(0.91)$ \\
\hline
\end{tabular}

\section{Conclusion}

The aim of this study was to develop ergonomic, high-sensitive protective footwear for firefighters that considered comfort of the wearers, active in the field. Therefore, an examination of the current conditions of protective footwear for firefighters in Korea was conducted, and designs were proposed based on the findings. Three designs that were submitted to the Firefighting Industry Excellent Design Competition were developed as test products, and wearability evaluation surveys were conducted on the products.

As a result of analyzing the current conditions of protective footwear worn by firefighters in Korea, it was confirmed that there was a need to improve the opening for better size and a close fit at the ankles. A need was also found to improve water-resistance, ventilation, and visibility, through a change of materials. Therefore, the opening was changed from the existing pull cord and zipper to laces and buckles, which made size adjustments possible and fit closer to the ankles. For materials, artificial leather with high water-resistance and ventilation was selected instead of the existing rubber material.

Test products I, II, and III were developed reflecting the design proposals above. Artificial leather and rubber were used for the test products with improved designs, and the opening was the laces and buckles type. Size adjustments were made possible to fit the body well, and closer contact was created at the ankles. The design and wearability evaluation survey on test products I, II, and III showed that the majority were satisfied with the design and wearability of all three test products.

The limitations of this study and suggestions for future studies are as follows. The range of this study was limited to design proposal and development of test products of protective footwear for firefighters. Future studies should improve the material, and produce protective footwear for firefighters that consider water-resistance, ventilation, and light weight. Ergonomic evaluations should be conducted in an environment with KFI certification, that is similar to the actual environment where firefighters work. The results of this study were development of designs for high-sensitive protective footwear for firefighters that considered convenience for firefighters active in the field, and are expected to be useful as foundation material for research and development of future protective footwear products for firefighters. 


\section{Authors' contributions}

SL conceived the work and MK prepared the samples and performed the analyzed. MK and SL are participated in the sequence alignment and drafted the manuscript. Both authors read and approved the final manuscript.

\section{Author details}

${ }^{1}$ Department of Fashion and Textiles, Dong-A University, Busan 49315, South Korea. ${ }^{2}$ Department of Fashion Design, Dong-A University, Busan 49315, South Korea.

\section{Acknowledgements}

This research was supported by Research Program To Solve Social Issues of the National Research Foundation of Korea (NRF) funded by the Ministry of Science and ICT (No. 2015M3C8A7A02027384).

\section{Competing interests}

The authors declare that they have no competing interests.

Ethics approval and consent to participate

Not applicable.

\section{Publisher's Note}

Springer Nature remains neutral with regard to jurisdictional claims in published maps and institutional affiliations.

Received: 7 July 2017 Accepted: 2 March 2018

Published online: 22 August 2018

\section{References}

Bang, C. H. (2010). A study on wearing practice of personal protective equipment for fire fighter: focusing on Gyeongnam province. Journal of Korean Society of Hazard Mitigation, 10(6), 65-71.

Huang, C. J., Garten, R. S., Wade, C., Webb, H. E., \& Acevedo, E. O. (2009). Physiological responses to simulated stair climbing in professional firefighters wearing rubber and leather boots. Journal of American Physiological Society, 107, 163-168. https://doi.org/10.1007/s00421-009-1092-8.

Huh, Y. S., \& Bang, C. H. (2013). Effect of wearing fire leather boot for physical balance. Journal of Korean Society of Hazard Mitigation, 13(4), 171-175. https://doi.org/10.9798/KOSHAM.2013.13.4.171.

International Organization for Standardization. (2001). ISO 15538:2001 Protective clothing for firefighters-Laboratory test methods and performance requirements for protective clothing with a reflective outer surface. Geneva: International Organization for Standardization

Jung, I., Kang, M., Lee, S. \& An, S. (2016). Product analysis and design suggestion for Korean fire-fighting shoes. Paper presented at the Asian Protective Clothing Summer Conference, Melbourne.

Kang, M., An, S. \& Lee, S. (2015). Product analysis of fire protection personal protective equipment-focused on protective footwear for firefighters, Proceedings of the Korean Society of Clothing and Textiles, Fall Conference, Korea, (p. 55).

Korea Fire Industry Technology Institute. (2001). KFIS 008: Standard for the protective footwear for firefighters. Yongin: Korea Fire Industry Technology Institute.

Lee, S. \& An, S. (2016). Analysis of wearing situation of fire boots, Proceedings of the Korean Society of Clothing and Textiles, Spring Conference, Korea, (p. 117)

National Fire Protection association. (2013). NFPA 1971:2013 standard on protective ensembles for structural firefighting and proximity firefighting. US: National Fire Protection association.

Safety Protection Standards. (2012). CSN EN 15090:2012 footwear for firefighters. CZE: Safety Protection Standards.

\section{Submit your manuscript to a SpringerOpen ${ }^{\circ}$ journal and benefit from:}

- Convenient online submission

Rigorous peer review

Open access: articles freely available online

- High visibility within the field

- Retaining the copyright to your article

Submit your next manuscript at $\boldsymbol{\Delta}$ springeropen.com 